\title{
Stereotactic radiosurgery to the resection bed for intracranial metastases and risk of leptomeningeal carcinomatosis
}

\author{
Clinical article
}

\author{
Eric OJerholm, M.D., ${ }^{1}$ John Y. K. Lee, M.D., ${ }^{2}$ JaYesh P. Thawani, M.D., ${ }^{2}$ \\ Denise Miller, B.S.N., ${ }^{2}$ Donald M. O'Rourke, M.D., ${ }^{2}$ JaY F. Dorsey, M.D., Ph.D., ${ }^{1}$ \\ Geoffrey A. Geiger, M.D., ${ }^{1}$ Suneel Nagda, M.D., ${ }^{1}$ JAmes D. KolKer, M.D., ${ }^{1}$ \\ Robert A. Lustig, M.D., ${ }^{1}$ and Michelle Alonso-Basanta, M.D., Ph.D. ${ }^{1}$ \\ Departments of ${ }^{1}$ Radiation Oncology and ${ }^{2}$ Neurosurgery, University of Pennsylvania, Philadelphia, \\ Pennsylvania
}

\begin{abstract}
Object. Following resection of a brain metastasis, stereotactic radiosurgery (SRS) to the cavity is an emerging alternative to postoperative whole-brain radiation therapy (WBRT). This approach attempts to achieve local control without the neurocognitive risks associated with WBRT. The authors aimed to report the outcomes of a large patient cohort treated with this strategy.

Methods. A retrospective review identified 91 patients without a history of WBRT who received Gamma Knife (GK) SRS to 96 metastasis resection cavities between 2007 and 2013. Patterns of intracranial control were examined in the 86 cases with post-GK imaging. Survival, local failure, and distant failure were estimated by the KaplanMeier method. Prognostic factors were tested by univariate (log-rank test) and multivariate (Cox proportional hazards model) analyses.

Results. Common primary tumors were non-small cell lung (43\%), melanoma (14\%), and breast (13\%). The cases were predominantly recursive partitioning analysis Class I $(25 \%)$ or II (70\%). Median preoperative metastasis diameter was $2.8 \mathrm{~cm}$, and $82 \%$ of patients underwent gross-total resection. A median dose of 16 Gy was delivered to the $50 \%$ isodose line, encompassing a median treatment volume of $9.2 \mathrm{~cm}^{3}$. Synchronous intact metastases were treated in addition to the resection bed in $43 \%$ of cases. Patients survived a median of 22.3 months from the time of GK. Local failure developed in 16 cavities, for a crude rate of $18 \%$ and 1 -year actuarial local control of $81 \%$. Preoperative metastasis diameter $\geq 3 \mathrm{~cm}$ and residual or recurrent tumor at the time of GK were associated with local failure ( $p=0.04$ and 0.008 , respectively). Distant intracranial failure occurred in 55 cases $(64 \%)$ at a median of 7.3 months from GK. Salvage therapies included WBRT and additional SRS in 33\% and 31\% of patients, respectively. Leptomeningeal carcinomatosis developed in 12 cases (14\%) and was associated with breast histology and infratentorial cavities ( $\mathrm{p}=0.024$ and 0.012 , respectively).

Conclusions. This study bolsters the existing evidence for SRS to the resection bed. Local control rates are high, but patients with larger preoperative metastases or residual/recurrent tumor at the time of SRS are more likely to fail at the cavity. While most patients develop distant intracranial failure, an SRS approach spared or delayed WBRT in the majority of cases. The risk of leptomeningeal carcinomatosis does not appear to be elevated with this strategy. (http://thejns.org/doi/abs/10.3171/2014.6.GKS14708)
\end{abstract}

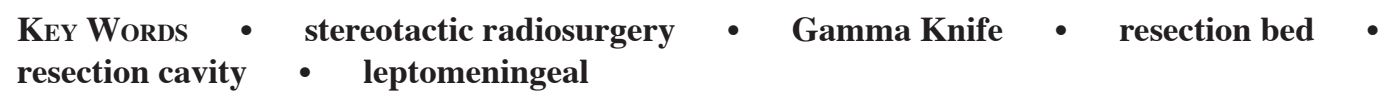

$\mathrm{B}$ RAIN metastases are the most frequent intracranial tumors in adults, with an incidence approaching $20 \%$ in some oncological populations. ${ }^{5}$ Management options include surgery, whole-brain radiation therapy (WBRT), and stereotactic radiosurgery (SRS). For patients who undergo resection, the standard of care is

\footnotetext{
Abbreviations used in this paper: $\mathrm{GK}=$ Gamma Knife; GTR = gross-total resection; LMC = leptomeningeal carcinomatosis; RPA = recursive partitioning analysis; SRS = stereotactic radiosurgery; $\mathrm{WBRT}=$ whole-brain radiation therapy.
}

postoperative WBRT. $32,44,49$ In this setting, WBRT reduces tumor recurrences at the resection cavity and at distant brain sites..$^{25,35}$ There are concerns, however, about the effect of WBRT on neurocognition and quality of life. . $11,31,42,47$ Over the past several years an alternative strategy of SRS to the surgical resection bed has emerged. The goal of this approach is to maintain local control at the cavity while delaying or avoiding the need for WBRT. The patient best suited for this technique and the prognostic factors associated with tumor control continue to be defined. In this article, we report the outcomes 
of a large cohort of patients treated with SRS to the resection bed. We quantify the risk of leptomeningeal carcinomatosis, data that have been rarely reported in previous studies. We end by summarizing the existing literature and discussing future directions for this strategy.

\section{Methods}

\section{Data Collection}

With the approval of the institutional review board, we retrospectively examined the medical records of all patients receiving Gamma Knife (GK) SRS to an intracranial surgical bed after resection of a brain metastasis between 2007 and 2013 at Pennsylvania Hospital. Patients were excluded if they had a history of WBRT before GK or an upfront plan for GK followed by WBRT. Patients with no clinical follow-up were excluded. We included patients who died before the first post-GK imaging study could be obtained. Because this initial surveillance scan was typically obtained 2-3 months after GK, restricting the study to only patients with follow-up imaging would have artificially inflated the survival rate of the cohort. Patient and disease characteristics were collected from the electronic medical record. The extent of surgery was determined by MRI 24 hours postoperatively, with a gross-total resection (GTR) denoting no evidence of enhancing residual tumor. Extracranial disease for patients whose primary tumor was previously treated was classified as none, stable, or progressive based on systemic imaging prior to GK. Cases in which the primary tumor was discovered at the same time as brain disease were classified as newly diagnosed, and the patients in these cases had not yet received treatment of the primary site. Recursive partitioning analysis (RPA) class was assigned according to Gaspar et al. ${ }^{10}$ Local tumor failure was defined as new or worsening nodular enhancement at the resection bed. All cases with radiological concern for local failure were additionally reviewed for consensus by 2 radiation oncologists (E.O. and M.A.B.), and advanced imaging modalities such as MRI perfusion were considered before final classification was made. Distant failure was defined as the development of new parenchymal brain metastases at sites away from the surgical cavity or the development of leptomeningeal carcinomatosis (LMC). Leptomeningeal carcinomatosis was diagnosed based on MRI, clinical symptoms, and/or cerebrospinal fluid cytology. Treatment volume for a resection cavity was defined as the volume of tissue receiving at least the prescribed marginal dose encompassing that cavity. For example, if a cavity was prescribed 15 Gy to the $50 \%$ isodose line, then the treatment volume for that cavity was the corresponding volume receiving $15 \mathrm{~Gy}$ or more. These values were calculated retrospectively using the GammaPlan software (Elekta $\mathrm{AB}$ ). Dates of death were confirmed via the medical record, Social Security Death Index, or online newspaper obituaries.

\section{Radiosurgical Technique and Follow-Up}

On the day of GK, patients were fitted with a Leksell stereotactic head frame under local anesthesia and con- scious sedation. Brain MR images were then obtained at 1-mm slices with double-dose gadolinium contrast. Treatment was delivered via a Model 4-C or Perfexion GK (Elekta $\mathrm{AB}$ ), targeting the surgical cavity and the surrounding enhancing tissue without an additional margin. Synchronous intact metastases were treated with GK during the same session. After the procedure, patients recovered in the GK suite and frames were removed. Antiepileptic agents were not routinely given, and steroids were administered at the treating physician's discretion. After GK, follow-up included clinical visits (typically at 1 month and then at 3-month intervals) as well as surveillance brain MRIs (typically at 2-3 months and then every 3 months).

\section{Statistical Analysis}

Overall survival was computed using the KaplanMeier method, and all cases were included in the analysis. Living patients or those lost to follow-up were censored at the date of last clinical encounter in the health system. Local and distant failure was examined by the KaplanMeier method in cases with available post-GK imaging. For these analyses, patients who received salvage WBRT were censored at last MRI before WBRT but continued to be followed for toxicity and survival. All cases were examined for the use of salvage therapies. Statistical tests were performed using Stata 12 (StataCorp). Univariate analyses were computed with the log-rank test and multivariate analyses via the Cox proportional hazards model. Hazard ratios and confidence intervals were noted. A p value $<0.05$ was considered statistically significant, and no adjustment was performed for multiple comparisons.

\section{Results}

The study cohort consisted of 91 patients with 96 treated resection cavities. Patient and disease characteristics are shown in Table 1 . The most common primary tumors were non-small cell lung (43\%), melanoma (14\%), and breast (13\%). Brain metastases were discovered a median of 20 months after initial diagnosis of the primary tumor (range 0-204 months). Extracranial disease was newly diagnosed or progressive in 42 cases (46\%), while the remaining 49 patients (54\%) had either stable disease or no evidence of tumor outside the brain. The majority of cases were RPA Class II (70\%). A gross-total resection was achieved in 79 cavities (82\%), and a subtotal resection in 17 (18\%). Stereotactic radiosurgery was performed a median of 6 weeks after resection (range 1-12 weeks). At the time of GK treatment planning, 17 patients with a GTR on 24-hour postoperative MRI had scans concerning for local recurrence in the cavity. In total, 34 cavities had concern for residual or recurrent tumor at the time of SRS. A typical prescription dose was 16 Gy to the $50 \%$ isodose line, encompassing a median treatment volume of $9.2 \mathrm{~cm}^{3}$. In addition to the resection bed, a median of 2 synchronous intact metastases (range 1-6) were treated in 39 patients $(43 \%)$.

\section{Local Failure}

Eighty-six patients with 91 treated cavities had follow-up imaging. Local failure developed in 16 cavities 
TABLE 1: Patient and disease characteristics*

\begin{tabular}{|c|c|}
\hline Characteristic & No. $(\%)$ \\
\hline \multicolumn{2}{|l|}{$\operatorname{sex} \dagger$} \\
\hline men & $36(40)$ \\
\hline women & $55(60)$ \\
\hline \multicolumn{2}{|l|}{ age in yrs at GK† } \\
\hline median & 60 \\
\hline range & $22-82$ \\
\hline \multicolumn{2}{|l|}{ primary tumor† } \\
\hline NSCLC & $39(43)$ \\
\hline melanoma & $13(14)$ \\
\hline breast & $12(13)$ \\
\hline colorectal & $8(9)$ \\
\hline renal & $6(7)$ \\
\hline sarcoma & $3(3)$ \\
\hline esophageal & $2(2)$ \\
\hline ovarian & $2(2)$ \\
\hline bladder & $1(1)$ \\
\hline oropharynx & $1(1)$ \\
\hline endometrial & $1(1)$ \\
\hline thyroid & $1(1)$ \\
\hline testicular & $1(1)$ \\
\hline unknown adenocarcinoma & $1(1)$ \\
\hline \multicolumn{2}{|l|}{ extracranial disease $\dagger$} \\
\hline newly diagnosed/progressing & $42(46)$ \\
\hline none/stable & $49(54)$ \\
\hline \multicolumn{2}{|l|}{ RPA class $†$} \\
\hline I & $23(25)$ \\
\hline$\|$ & $64(70)$ \\
\hline III & $4(4)$ \\
\hline \multicolumn{2}{|l|}{ preop diameter in cm $\ddagger$} \\
\hline median & 2.8 \\
\hline range & $0.8-6.9$ \\
\hline \multicolumn{2}{|l|}{ tumor location $\ddagger$} \\
\hline supratentorial & $74(77)$ \\
\hline infratentorial & $22(23)$ \\
\hline \multicolumn{2}{|l|}{ surgery extentł } \\
\hline GTR & $79(82)$ \\
\hline STR & $17(18)$ \\
\hline \multicolumn{2}{|l|}{ wks from resection to GK† } \\
\hline median & 6 \\
\hline range & $1-12$ \\
\hline \multicolumn{2}{|l|}{ marginal cavity dose in Gył } \\
\hline median & 16 \\
\hline range & $12-21$ \\
\hline \multicolumn{2}{|l|}{ isodose level in \%‡ } \\
\hline median & 50 \\
\hline range & $40-70$ \\
\hline
\end{tabular}

(continued)
TABLE 1: Patient and disease characteristics* (continued)

\begin{tabular}{cl}
\hline \multicolumn{1}{c}{ Characteristic } & No. (\%) \\
\hline treatment vol in $\mathrm{cm}^{3} \ddagger$ & \\
median & 9.2 \\
range & $0.6-34.7$ \\
synchronous intact mets $\dagger$ & \\
yes & $39(43)$ \\
no & $52(57)$ \\
\hline
\end{tabular}

* Mets = metastases; NSCLC $=$ non-small cell lung cancer; STR = subtotal resection.

$\dagger \mathrm{N}=91$ patients.

$\ddagger N=96$ resection cavities.

for a crude rate of $18 \%$. According to the Kaplan-Meier method, 1-year actuarial local control was $81 \%$ (Fig. 1). On univariate analysis, factors associated with local failure were breast histology, infratentorial location, preoperative metastasis diameter $\geq 3 \mathrm{~cm}$, and residual or recurrent tumor in the cavity at the time of GK (Table 2). On multivariate analysis, preoperative metastasis diameter and residual/recurrent tumor were significantly associated with local failure ( $\mathrm{p}=0.04$, HR $3.7,95 \%$ CI $1.04-13.3$ and $p=0.008$, HR $4.8,95 \%$ CI 1.5-15.3, respectively).

\section{Distant Failure}

Among the 86 patients with follow-up imaging, 55 (64\%) developed distant intracranial failure at a median of 7.3 months from GK (Fig. 2). On univariate analysis, treatment volume over $10 \mathrm{~cm}^{3}$ and residual/recurrent tumor at the time of GK showed some association with distant failure ( $\mathrm{p}=0.09$ and 0.11 , respectively). No other tested factor was correlated (primary histology, status of extracranial disease, presence of synchronous metastases, or time from surgery to GK). On multivariate analysis, no factor was significantly associated with distant failure.

\section{Leptomeningeal Carcinomatosis}

Among the 86 cases with follow-up imaging, 12 developed leptomeningeal carcinomatosis (LMC) for a crude rate of $14 \%$. On univariate analysis, breast histology and

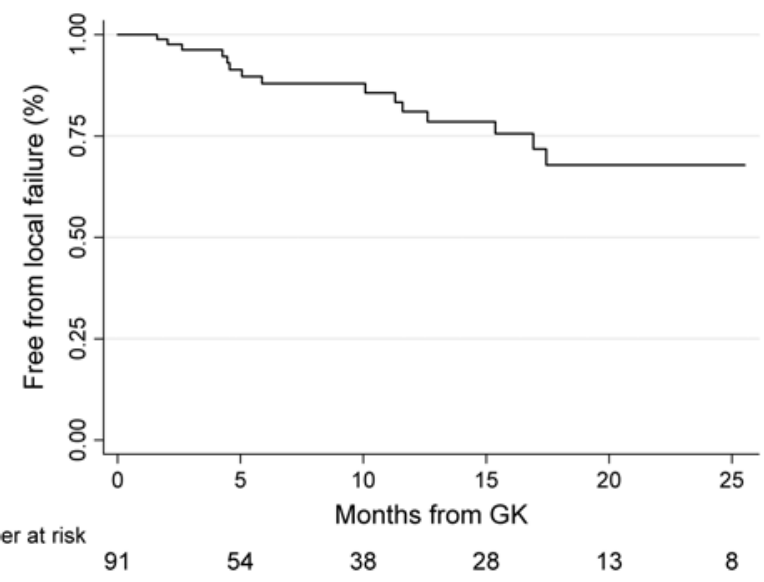

FIG. 1. Freedom from local tumor failure after GK SRS. 
TABLE 2: Local failure analysis

\begin{tabular}{lcc}
\hline & \multicolumn{2}{c}{$p$ Value } \\
\cline { 2 - 3 } \multicolumn{1}{c}{ Characteristic } & $\begin{array}{c}\text { Univariate } \\
\text { Analysis }\end{array}$ & $\begin{array}{c}\text { Multivariate } \\
\text { Analysis }\end{array}$ \\
\hline histology (breast vs other) & 0.063 & 0.14 \\
cavity location (infratentorial vs not) & 0.056 & 0.15 \\
preop tumor size ( $\geq 3 \mathrm{~cm}$ vs not) & 0.078 & 0.04 \\
wks from resection to GK ( $\geq 6$ vs not) & 0.64 & - \\
prescribed dose ( $<16 \mathrm{~Gy}$ vs not) & 0.91 & - \\
treatment vol ( $\geq 10 \mathrm{~cm}^{3}$ vs not) & 0.27 & - \\
residual/recurrent tumor at GK & 0.004 & 0.008 \\
\hline
\end{tabular}

infratentorial cavity location were associated with LMC (Table 3). On multivariate analysis, both factors were independent, statistically significant predictors of LMC ( $p$ $=0.024$, HR 3.8, 95\% CI 1.2-12.4 and $\mathrm{p}=0.012$, HR 4.6, $95 \%$ CI 1.4-14.9, respectively).

\section{Overall Survival}

At the time of analysis, 38 patients (42\%) had died. The median clinical follow-up for the 53 living patients was 15.3 months (range 2.2-50.8 months) and for the entire cohort was 9.8 months (range 0.4-64.5 months). Based on the Kaplan-Meier method, the median overall survival was 22.3 months from SRS. On univariate analysis, the only factor associated with survival was active extracranial disease $(p=0.05)$. Specifically, patients with progressive systemic disease or those with newly diagnosed, untreated primary lesions had worse survival compared to patients with stable extracranial disease or those with no evidence of tumor outside the brain. As only a single factor was associated on univariate analysis, no multivariate analysis was performed.

\section{Survival With Intracranial Control}

Some patients survived and maintained intracranial tumor control for a considerable time after SRS (Fig. $3)$. Kaplan-Meier analysis revealed 23 patients alive and without local or distant brain failure at 12 months, 9 at 20 months, and 4 at 30 months following GK.

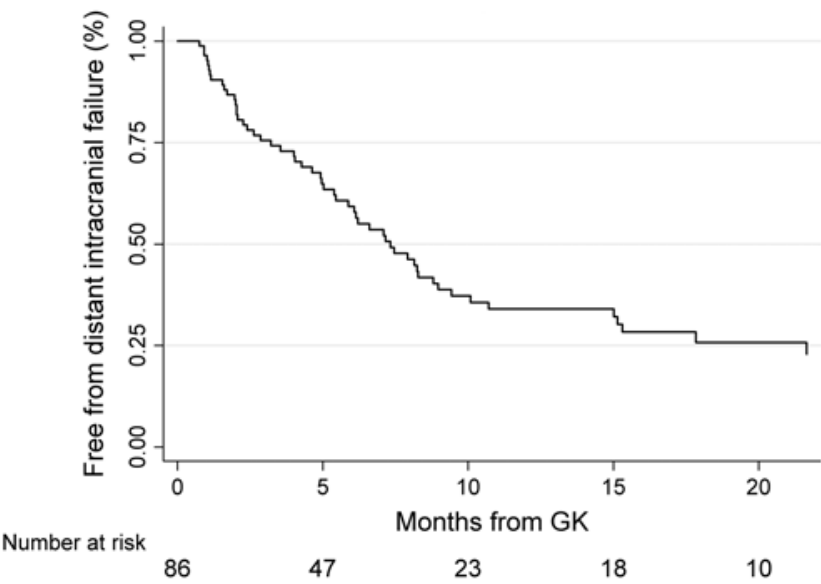

FIG. 2. Freedom from distant intracranial failure after GK SRS.
TABLE 3: Association with LMC

\begin{tabular}{llc}
\hline & \multicolumn{2}{c}{$p$ Value } \\
\cline { 2 - 3 } \multicolumn{1}{c}{ Characteristic } & $\begin{array}{c}\text { Univariate } \\
\text { Analysis }\end{array}$ & $\begin{array}{c}\text { Multivariate } \\
\text { Analysis }\end{array}$ \\
\hline histology (breast vs other) & 0.0027 & 0.024 \\
extent of resection (STR vs GTR) & 0.44 & - \\
cavity location (infratentorial vs not) & 0.0014 & 0.012 \\
synchronous mets (yes vs no) & 0.88 & - \\
intracranial progression (yes vs no) & 0.92 & - \\
treatment vol ( $\geq 10 \mathrm{~cm}^{3}$ vs not) & 0.96 & - \\
\hline
\end{tabular}

\section{Salvage Therapies}

Thirty of 91 patients (33\%) were salvaged with WBRT at a median of 6.1 months after GK. Salvage SRS (either GK or CyberKnife) was performed in 28 cases (31\%). See Fig. 4 for details of salvage radiation therapy. Seventeen patients underwent additional neurosurgical procedures after initial GK.

\section{Adverse Events}

Six of 91 patients developed symptomatic radionecrosis requiring administration of steroids. Neurosurgical resection of radionecrosis was performed in 2 cases. Three patients had new seizures within 3 months of GK requiring initiation of antiepileptic treatment or hospitalization.

\section{Discussion}

\section{The Rationale for SRS to the Resection Bed}

Patients with brain metastases may undergo surgery for pathological diagnosis or to relieve mass effect. Postoperative WBRT is the established standard of care. . $^{32,44,49}$ Randomized trials show that WBRT improves tumor control at both the resection cavity and at distant brain sites without extending overall survival or functional independence. ${ }^{25,35}$ However, potential detrimental side effects of WBRT have played an important role in spurring

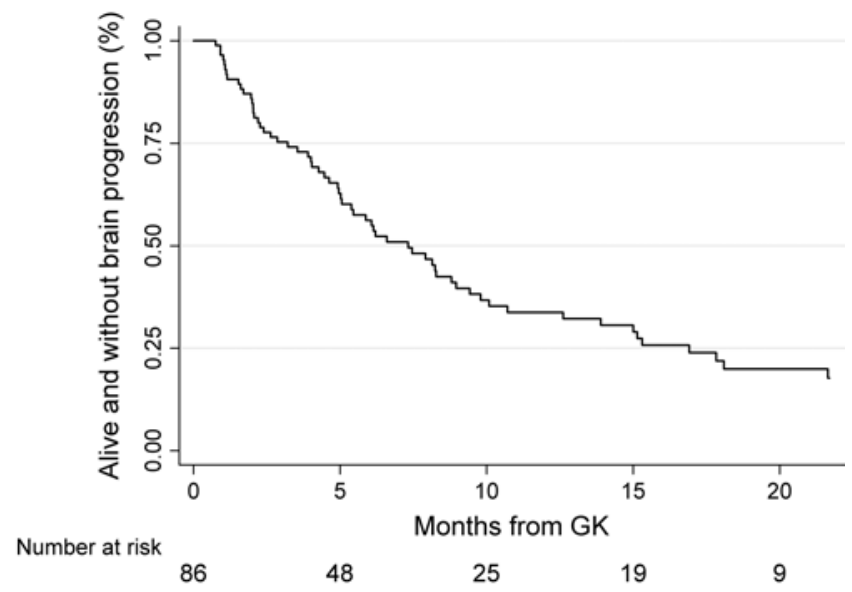

Fig. 3. Survival without intracranial tumor progression (local or distant) after GK SRS. 


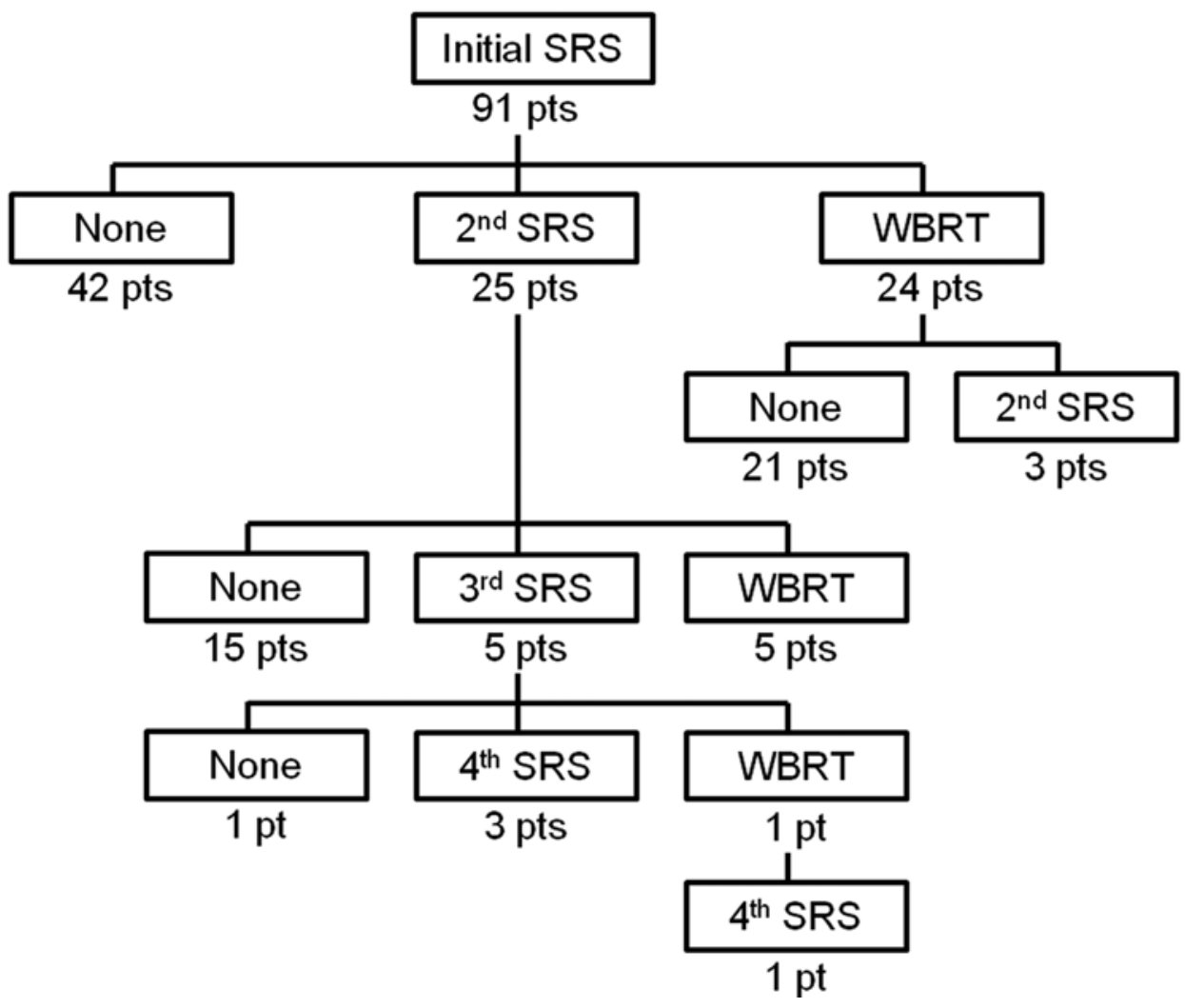

FIG. 4. Salvage radiation treatments following initial SRS to the surgical bed. pts = patients.

the investigation of SRS alone. ${ }^{44}$ Several randomized trials have bolstered these concerns, demonstrating declines in cognitive function and health-related quality of life in patients receiving WBRT, ${ }^{7,11,31,42,47}$ However, none of these studies specifically compared WBRT to SRS alone in the postoperative setting. Other data suggest that an increase in intracranial tumor burden, rather than WBRT, is the principal driver of neurocognitive decline., ${ }^{1,26,38}$ Significant rates of distant brain relapse are a recognized downside to the SRS-only approach, ${ }^{28}$ and whether this offsets the potential benefit of avoiding WBRT remains to be answered. Indeed, neurocognition is a primary end point of the ongoing Phase III trial of WBRT versus SRS following resection (NCCTG-N107C). Apart from the side effects of WBRT, SRS has the advantage of single-session delivery. This may be particularly important to avoiding delays in chemotherapy for patients with newly diagnosed primary tumors or progressing systemic disease, a group comprising $46 \%$ of our cohort.

\section{The Current Evidence for SRS}

As we await Level I evidence on the strategy of SRS to the resection bed, what tentative conclusions can clinicians glean from over 1100 total cases (Table 4) now reported in the literature? $6,8,9,12,14-16,18,21-24,27-29,33,36,39$ The typical patient is RPA Class II and status post GTR of a single non-small cell lung cancer metastasis. The 5 largest cohorts, including the present study, demonstrate crude recurrence rates at the resection cavity of $11 \%-19 \%$, with a 1-year actuarial local control ranging from $81 \%$ to $91 \% 8^{8,18,28,39}$ Series of postoperative WBRT have reported local recurrence rates between $10 \%$ and $27 \%, 30,35,40$ It is important to note that direct comparisons across different published cohorts are limited by multiples biases. With this caveat, it appears that SRS may achieve similar control rates at the resection cavity as WBRT. The available evidence (Table 4) in aggregate demonstrates that about $53 \%$ of patients will develop new distant brain metastases and about $32 \%$ will be salvaged with WBRT. The substantial rate of distant failure highlights the importance of close clinical and imaging followup for patients treated with this technique.

\section{Survival and Intracranial Tumor Control}

Factors that correlate with survival and intracranial tumor control are varied and conflicting in the existing literature. Our finding that patients with active extracranial disease have worse survival supports similar conclusions by prior authors, ${ }^{8,16,33,43}$ although other studies have explicitly reported no correlation. ${ }^{6,21}$ Prognostic factors for local control are also in dispute, particularly relating to size and volume. Multiple studies, including ours, have demonstrated no correlation between treatment volume and local failure. . $8,12,22,29,33,43$ Other series have reached the opposite conclusion. ${ }^{16,28,36,39,40}$ Our data echo the findings of Jensen et al. and Brennan et al. that preoperative tumors $\geq 3 \mathrm{~cm}$ are at higher risk for local failure despite treatment volume being unrelated. ${ }^{6,18}$ Perhaps, as suggested by Brennan et al., larger tumors reflect a more aggressive biology and make for a more technically difficult resection. ${ }^{6}$ We also found that residual or recurrent tumor 
E. Ojerholm et al.

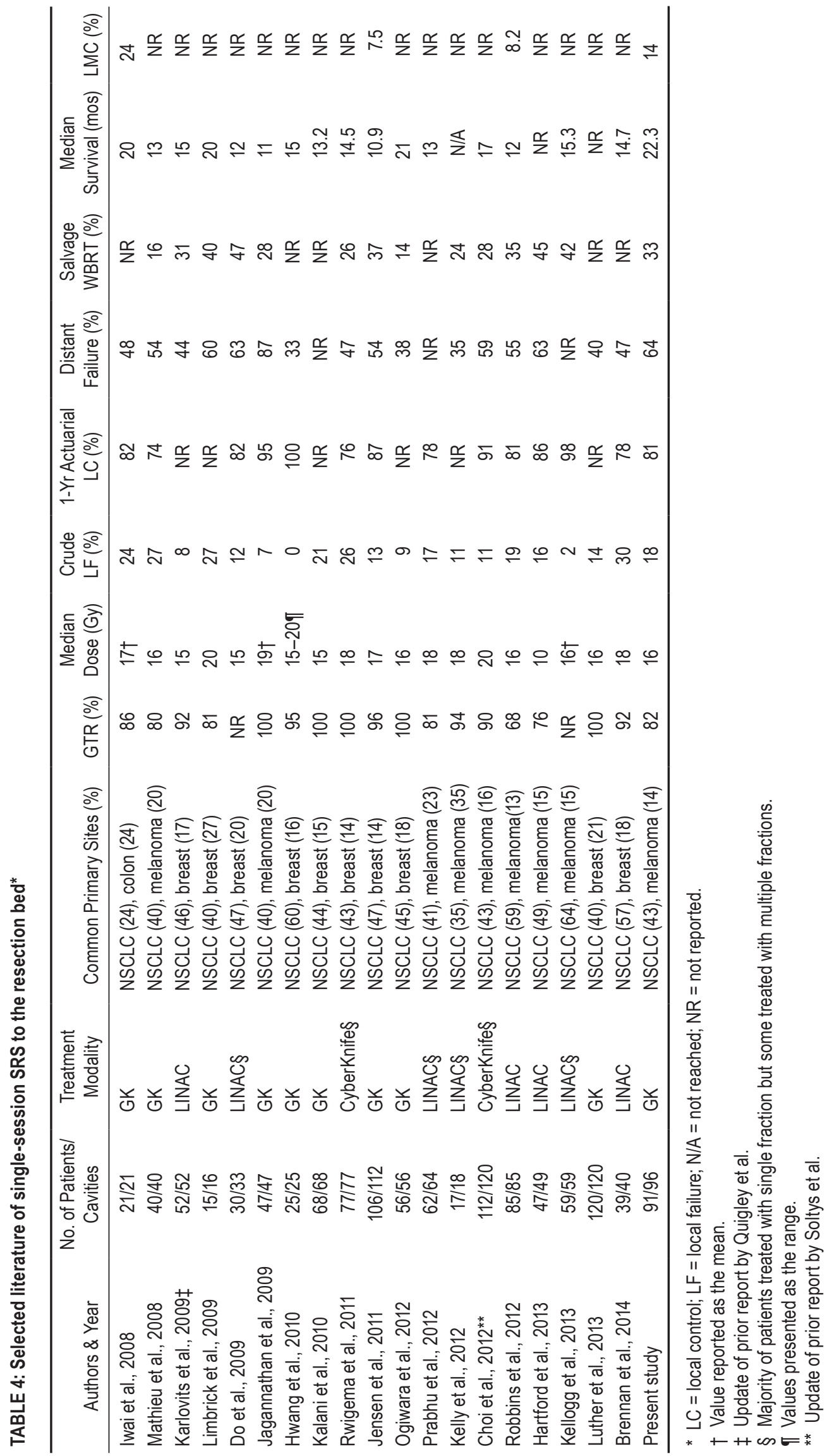




\section{Radiosurgery to the resection bed for brain metastases}

in the resection cavity was predictive of local failure. It is unclear whether earlier treatment would have been advantageous for patients who initially had a GTR and recurred by the GK planning scan, and time to radiosurgery was not significant in our models. However, 2 recent studies revealed that most resection cavities do not shrink over time after surgery, suggesting that GK should be performed shortly thereafter. ${ }^{3,17}$

\section{Leptomeningeal Carcinomatosis}

In theory, resection of a metastasis may seed cerebrospinal fluid and elevate the risk of leptomeningeal carcinomatosis (LMC). ${ }^{20,41}$ Adjuvant WBRT holds a hypothetical advantage over focal SRS for sterilizing the meninges. However, LMC is not well reported in prior SRS series. The rate was $24 \%$ in a small early experience ${ }^{15}$ but about $8 \%$ in 2 larger studies. ${ }^{18,39}$ Only the first series analyzed factors associated with LMC, finding infratentorial lesions at higher risk. ${ }^{15}$ More recently, Atalar and colleagues updated a previous SRS cohort ${ }^{8}$ with a focus on LMC. ${ }^{4}$ They reported a rate of $13 \%$ and found breast histology to be the only associated factor. ${ }^{4}$ Our rate of $14 \%$ confirms this prior study, and we demonstrated a significant independent association for both breast histology and infratentorial cavity location. Are patients who undergo SRS to the resection bed at elevated risk for LMC? In general, the overall incidence of LMC in solid malignancies ranges from 5\% to $15 \% .48$ The rates were $5 \%$ and $10 \%$ following resection (mostly without adjuvant radiation) for supratentorial and infratentorial lesions in 2 large surgical series ${ }^{45,46} \mathrm{In}$ a cohort of 66 patients treated with resection followed by WBRT, $11 \%$ developed LMC..$^{13}$ The incidence was $13 \%$ in a recent study of SRS alone to multiple intact metastases. ${ }^{34}$ Additionally, data on whether WBRT reduces the risk of LMC are conflicting. ${ }^{19,46}$ Differences in patient populations and definitions of LMC make comparisons between these studies challenging. However, the available evidence suggests that patients treated with SRS to the resection cavity have similar rates of LMC as patients in other settings. Prospective trials are needed to fully answer this question.

\section{Future Directions for SRS}

A major anticipated advance will be the reporting of the North Central Cancer Treatment Group N107C study. This multi-institutional trial randomizes patients to WBRT or cavity-directed SRS following resection of a single metastasis. The primary end points are overall survival and neurocognition at 6 months following radiotherapy. Future studies will also help identify which patients benefit most from this strategy. In our cohort, some patients fared poorly and required salvage WBRT within weeks of GK, while others lived years without any intracranial progression (Fig. 3). More data will aid in appropriately tailoring postoperative radiotherapy, whether WBRT or SRS. Another area of future investigation is neoadjuvant SRS. Asher and colleagues recently reported results of SRS delivered before planned resection. ${ }^{2}$ Theoretical advantages to this approach include clearer target delineation, higher delivered dose, and treatment while the tumor has an intact blood supply.

\section{Limitations}

Our study is limited by the biases of a retrospective analysis. Additionally, we lacked data on neurocognitive function after GK and did not record whether deaths were from neurological progression. These limitations will be addressed by the NCCTG-N107C randomized trial.

\section{Conclusions}

This large retrospective cohort bolsters the existing evidence for SRS to the surgical resection bed. Local control rates are high, but patients with larger preoperative metastases or residual/recurrent tumor at the time of SRS are more likely to fail at the cavity. While most patients develop distant intracranial failure, an SRS approach spared or delayed WBRT for a majority of cases. The risk of leptomeningeal carcinomatosis does not appear to be elevated with this strategy.

\section{Acknowledgments}

We thank Abigail T. Berman, M.D., and Anusha Kalbasi, M.D., for their helpful suggestions.

\section{Disclosure}

The authors report no conflict of interest concerning the materials or methods used in this study or the findings specified in this paper.

Author contributions to the study and manuscript preparation include the following. Conception and design: Alonso-Basanta, Ojerholm, Lee. Acquisition of data: Alonso-Basanta, Ojerholm, Thawani, Miller. Analysis and interpretation of data: Alonso-Basanta, Ojerholm, Lee, Thawani, O’Rourke, Dorsey, Geiger, Nagda, Kolker, Lustig. Drafting the article: Ojerholm. Critically revising the article: all authors. Reviewed submitted version of manuscript: all authors. Statistical analysis: Ojerholm. Administrative/technical/material support: Miller. Study supervision: Alonso-Basanta.

\section{References}

1. Aoyama H, Tago M, Kato N, Toyoda T, Kenjyo M, Hirota S, et al: Neurocognitive function of patients with brain metastasis who received either whole brain radiotherapy plus stereotactic radiosurgery or radiosurgery alone. Int $\mathbf{J}$ Radiat Oncol Biol Phys 68:1388-1395, 2007

2. Asher AL, Burri SH, Wiggins WF, Kelly RP, Boltes MO, Mehrlich M, et al: A new treatment paradigm: neoadjuvant radiosurgery before surgical resection of brain metastases with analysis of local tumor recurrence. Int J Radiat Oncol Biol Phys 88:899-906, 2014

3. Atalar B, Choi CY, Harsh GR IV, Chang SD, Gibbs IC, Adler JR, et al: Cavity volume dynamics after resection of brain metastases and timing of postresection cavity stereotactic radiosurgery. Neurosurgery 72:180-185, 2013

4. Atalar B, Modlin LA, Choi CY, Adler JR, Gibbs IC, Chang $\mathrm{SD}$, et al: Risk of leptomeningeal disease in patients treated with stereotactic radiosurgery targeting the postoperative resection cavity for brain metastases. Int J Radiat Oncol Biol Phys 87:713-718, 2013

5. Barnholtz-Sloan JS, Sloan AE, Davis FG, Vigneau FD, Lai P, Sawaya RE: Incidence proportions of brain metastases in patients diagnosed (1973 to 2001) in the Metropolitan Detroit Cancer Surveillance System. J Clin Oncol 22:2865-2872, 2004

6. Brennan C, Yang TJ, Hilden P, Zhang Z, Chan K, Yamada Y, 
et al: A phase 2 trial of stereotactic radiosurgery boost after surgical resection for brain metastases. Int J Radiat Oncol Biol Phys 88:130-136, 2014

7. Chang EL, Wefel JS, Hess KR, Allen PK, Lang FF, Kornguth DG, et al: Neurocognition in patients with brain metastases treated with radiosurgery or radiosurgery plus whole-brain irradiation: a randomised controlled trial. Lancet Oncol 10: 1037-1044, 2009

8. Choi CY, Chang SD, Gibbs IC, Adler JR, Harsh GR IV, Lieberson RE, et al: Stereotactic radiosurgery of the postoperative resection cavity for brain metastases: prospective evaluation of target margin on tumor control. Int $\mathbf{J}$ Radiat Oncol Biol Phys 84:336-342, 2012

9. Do L, Pezner R, Radany E, Liu A, Staud C, Badie B: Resection followed by stereotactic radiosurgery to resection cavity for intracranial metastases. Int J Radiat Oncol Biol Phys 73:486-491, 2009

10. Gaspar L, Scott C, Rotman M, Asbell S, Phillips T, Wasserman $\mathrm{T}$, et al: Recursive partitioning analysis (RPA) of prognostic factors in three Radiation Therapy Oncology Group (RTOG) brain metastases trials. Int J Radiat Oncol Biol Phys 37:745751,1997

11. Gondi V, Paulus R, Bruner DW, Meyers CA, Gore EM, Wolfson A, et al: Decline in tested and self-reported cognitive functioning after prophylactic cranial irradiation for lung cancer: pooled secondary analysis of Radiation Therapy Oncology Group randomized trials 0212 and 0214. Int J Radiat Oncol Biol Phys 86:656-664, 2013

12. Hartford AC, Paravati AJ, Spire WJ, Li Z, Jarvis LA, Fadul $\mathrm{CE}$, et al: Postoperative stereotactic radiosurgery without whole-brain radiation therapy for brain metastases: potential role of preoperative tumor size. Int J Radiat Oncol Biol Phys 85:650-655, 2013

13. Hashimoto K, Narita Y, Miyakita Y, Ohno M, Sumi M, Mayahara $\mathrm{H}$, et al: Comparison of clinical outcomes of surgery followed by local brain radiotherapy and surgery followed by whole brain radiotherapy in patients with single brain metastasis: single-center retrospective analysis. Int J Radiat Oncol Biol Phys 81:e475-e480, 2011

14. Hwang SW, Abozed MM, Hale A, Eisenberg RL, Dvorak T, Yao K, et al: Adjuvant Gamma Knife radiosurgery following surgical resection of brain metastases: a 9-year retrospective cohort study. J Neurooncol 98:77-82, 2010

15. Iwai Y, Yamanaka K, Yasui T: Boost radiosurgery for treatment of brain metastases after surgical resections. Surg Neurol 69:181-186, 2008

16. Jagannathan J, Yen CP, Ray DK, Schlesinger D, Oskouian RJ, Pouratian N, et al: Gamma Knife radiosurgery to the surgical cavity following resection of brain metastases. Clinical article. J Neurosurg 111:431-438, 2009

17. Jarvis LA, Simmons NE, Bellerive M, Erkmen K, Eskey CJ, Gladstone DJ, et al: Tumor bed dynamics after surgical resection of brain metastases: implications for postoperative radiosurgery. Int J Radiat Oncol Biol Phys 84:943-948, 2012

18. Jensen CA, Chan MD, McCoy TP, Bourland JD, deGuzman $\mathrm{AF}$, Ellis TL, et al: Cavity-directed radiosurgery as adjuvant therapy after resection of a brain metastasis. Clinical article. J Neurosurg 114:1585-1591, 2011

19. Jo KI, Lim DH, Kim ST, Im YS, Kong DS, Seol HJ, et al: Leptomeningeal seeding in patients with brain metastases treated by gamma knife radiosurgery. J Neurooncol 109:293-299, 2012

20. Jung JM, Kim S, Joo J, Shin KH, Gwak HS, Lee SH: Incidence and risk factors for leptomeningeal carcinomatosis in breast cancer patients with parenchymal brain metastases. J Korean Neurosurg Soc 52:193-199, 2012

21. Kalani MY, Filippidis AS, Kalani MA, Sanai N, Brachman D, McBride HL, et al: Gamma Knife surgery combined with resection for treatment of a single brain metastasis: preliminary results. Clinical article. J Neurosurg 113 Suppl:90-96, 2010
22. Karlovits BJ, Quigley MR, Karlovits SM, Miller L, Johnson M, Gayou O, et al: Stereotactic radiosurgery boost to the resection bed for oligometastatic brain disease: challenging the tradition of adjuvant whole-brain radiotherapy. Neurosurg Focus 27(6):E7, 2009

23. Kellogg RG, Straus DC, Choi M, Chaudhry TA, Diaz AZ, Muñoz LF: Stereotactic radiosurgery boost to the resection cavity for cerebral metastases: Report of overall survival, complications, and corticosteroid protocol. Surg Neurol Int 4 (Suppl 6):S436-S442, 2013

24. Kelly PJ, Lin YB, Yu AY, Alexander BM, Hacker F, Marcus $\mathrm{KJ}$, et al: Stereotactic irradiation of the postoperative resection cavity for brain metastasis: a frameless linear acceleratorbased case series and review of the technique. Int J Radiat Oncol Biol Phys 82:95-101, 2012

25. Kocher M, Soffietti R, Abacioglu U, Villà S, Fauchon F, Baumert BG, et al: Adjuvant whole-brain radiotherapy versus observation after radiosurgery or surgical resection of one to three cerebral metastases: results of the EORTC 22952-26001 study. J Clin Oncol 29:134-141, 2011

26. Li J, Bentzen SM, Renschler M, Mehta MP: Regression after whole-brain radiation therapy for brain metastases correlates with survival and improved neurocognitive function. J Clin Oncol 25:1260-1266, 2007

27. Limbrick DD Jr, Lusis EA, Chicoine MR, Rich KM, Dacey RG, Dowling JL, et al: Combined surgical resection and stereotactic radiosurgery for treatment of cerebral metastases. Surg Neurol 71:280-289, 2009

28. Luther N, Kondziolka D, Kano H, Mousavi SH, Engh JA, Niranjan A, et al: Predicting tumor control after resection bed radiosurgery of brain metastases. Neurosurgery 73:1001-1006, 2013

29. Mathieu D, Kondziolka D, Flickinger JC, Fortin D, Kenny B, Michaud K, et al: Tumor bed radiosurgery after resection of cerebral metastases. Neurosurgery 62:817-824, 2008

30. McPherson CM, Suki D, Feiz-Erfan I, Mahajan A, Chang E, Sawaya R, et al: Adjuvant whole-brain radiation therapy after surgical resection of single brain metastases. Neuro Oncol 12:711-719, 2010

31. Muacevic A, Wowra B, Siefert A, Tonn JC, Steiger HJ, Kreth FW: Microsurgery plus whole brain irradiation versus Gamma Knife surgery alone for treatment of single metastases to the brain: a randomized controlled multicentre phase III trial. J Neurooncol 87:299-307, 2008

32. National Comprehensive Cancer Network: Central Nervous System Cancers, Version 1.2014. NCCN.org. March 11, 2014

33. Ogiwara H, Kalakota K, Rakhra SS, Helenowski IB, Marymont $\mathrm{MH}$, Kalapurakal JA, et al: Intracranial relapse rates and patterns, and survival trends following post-resection cavity radiosurgery for patients with single intracranial metastases. J Neurooncol 108:141-146, 2012

34. Ojerholm E, Lee JY, Kolker J, Lustig RA, Dorsey JF, AlonsoBasanta M: Gamma knife radiosurgery to four or more brain metastases in patients without prior intracranial radiation or surgery. Cancer Med 3:565-571, 2014

35. Patchell RA, Tibbs PA, Regine WF, Dempsey RJ, Mohiuddin M, Kryscio RJ, et al: Postoperative radiotherapy in the treatment of single metastases to the brain: a randomized trial. JAMA 280:1485-1489, 1998

36. Prabhu R, Shu HK, Hadjipanayis C, Dhabaan A, Hall W, Raore B, et al: Current dosing paradigm for stereotactic radiosurgery alone after surgical resection of brain metastases needs to be optimized for improved local control. Int J Radiat Oncol Biol Phys 83:e61-e66, 2012

37. Quigley MR, Fuhrer R, Karlovits S, Karlovits B, Johnson M: Single session stereotactic radiosurgery boost to the post-operative site in lieu of whole brain radiation in metastatic brain disease. J Neurooncol 87:327-332, 2008

38. Regine WF, Scott C, Murray K, Curran W: Neurocognitive 


\section{Radiosurgery to the resection bed for brain metastases}

outcome in brain metastases patients treated with acceleratedfractionation vs. accelerated-hyperfractionated radiotherapy: an analysis from Radiation Therapy Oncology Group Study 91-04. Int J Radiat Oncol Biol Phys 51:711-717, 2001

39. Robbins JR, Ryu S, Kalkanis S, Cogan C, Rock J, Movsas B, et al: Radiosurgery to the surgical cavity as adjuvant therapy for resected brain metastasis. Neurosurgery 71:937-943, 2012

40. Rwigema JC, Wegner RE, Mintz AH, Paravati AJ, Burton SA, Ozhasoglu C, et al: Stereotactic radiosurgery to the resection cavity of brain metastases: a retrospective analysis and literature review. Stereotact Funct Neurosurg 89:329-337, 2011

41. Siomin VE, Vogelbaum MA, Kanner AA, Lee SY, Suh JH, Barnett GH: Posterior fossa metastases: risk of leptomeningeal disease when treated with stereotactic radiosurgery compared to surgery. J Neurooncol 67:115-121, 2004

42. Soffietti R, Kocher M, Abacioglu UM, Villa S, Fauchon F, Baumert BG, et al: A European Organisation for Research and Treatment of Cancer phase III trial of adjuvant wholebrain radiotherapy versus observation in patients with one to three brain metastases from solid tumors after surgical resection or radiosurgery: quality-of-life results. J Clin Oncol 31:65-72, 2013

43. Soltys SG, Adler JR, Lipani JD, Jackson PS, Choi CY, Puataweepong P, et al: Stereotactic radiosurgery of the postoperative resection cavity for brain metastases. Int J Radiat Oncol Biol Phys 70:187-193, 2008

44. Suh JH, Videtic GM, Aref AM, Germano I, Goldsmith BJ, Imperato JP, et al: ACR Appropriateness Criteria: single brain metastasis. Curr Probl Cancer 34:162-174, 2010

45. Suki D, Abouassi H, Patel AJ, Sawaya R, Weinberg JS, Groves MD: Comparative risk of leptomeningeal disease after resection or stereotactic radiosurgery for solid tumor metastasis to the posterior fossa. J Neurosurg 108:248-257, 2008
46. Suki D, Hatiboglu MA, Patel AJ, Weinberg JS, Groves MD, Mahajan A, et al: Comparative risk of leptomeningeal dissemination of cancer after surgery or stereotactic radiosurgery for a single supratentorial solid tumor metastasis. Neurosurgery 64:664-676, 2009

47. Sun A, Bae K, Gore EM, Movsas B, Wong SJ, Meyers CA, et al: Phase III trial of prophylactic cranial irradiation compared with observation in patients with locally advanced non-smallcell lung cancer: neurocognitive and quality-of-life analysis. J Clin Oncol 29:279-286, 2011

48. Taillibert S, Laigle-Donadey F, Chodkiewicz C, Sanson M, Hoang-Xuan K, Delattre JY: Leptomeningeal metastases from solid malignancy: a review. J Neurooncol 75:85-99, 2005

49. Tsao MN, Rades D, Wirth A, Lo SS, Danielson BL, Gaspar LE, et al: Radiotherapeutic and surgical management for newly diagnosed brain metastasis(es): An American Society for Radiation Oncology evidence-based guideline. Pract Radiat Oncol 2:210-225, 2012

Manuscript submitted April 21, 2014.

Accepted June 25, 2014.

Portions of this work were presented in oral form at the 17th International Leksell Gamma Knife Society Meeting, New York, NY, May 11-15, 2014.

Please include this information when citing this paper: DOI: 10.3171/2014.6.GKS14708.

Address correspondence to: Michelle Alonso-Basanta, M.D., Ph.D., Department of Radiation Oncology, University of Pennsylvania, 3400 Civic Center Blvd., TRC 2 West, Philadelphia, PA 19104. email: michelleab@uphs.upenn.edu. 